\title{
Comprensión y reconciliación: algunas reflexiones en torno a Hannah Arendt
}

\section{Understanding and reconciliation: some reflections on Hannah Arendt}

\author{
JUAN IGNACIO BLANCO ILARI \\ Profesor de la Universidad Nacional de General Sarmiento (Argentina)
}

Recibido: 04/03/2013 Aceptado: 29/04/2013

\section{RESUMEN}

El pensamiento filosófico ha encontrado en el problema del mal un difícil y provocativo desafío. Cuando el mal aparece, el pensamiento llega a sus límites. El siglo veinte ha sido testigo del horror. El pensamiento necesita reconciliarse con un mundo en el que el horror ha sucedido. Hannah Arendt fue una de las intelectuales más importantes que enfatizó la relación entre comprensión y reconciliación. Para ella, la consecuencia inherente de la comprensión es la reconciliación. En este trabajo analizo el alcance de su argumento. Intento conectar la mirada arendtiana con otros autores que confrontan con su perspectiva.

\section{PALABRAS CLAVE}

HANNAH ARENDT, COMPRENSIÓN, RECONCILIACIÓN

\begin{abstract}
Philosophical thought found in the problem of evil a very difficult and provocative defiance. When evil appears, thought reaches its boundaries. The twentieth century witnessed horror. Thinking needs to reconcile with a world in which there has been horror. Hannah Arendt was one of the most important intellectuals who emphasised the relationship between understanding and reconciliation. For her, the inherent consequence of understanding is reconciliation.
\end{abstract}


In this paper I analyse the scope of her argument and try to connect Arendt's view with other authors that confront her perspective.

KEY WORDS

HANNAH ARENDT, UNDERSTANDING, RECONCILIATION

\section{INTRODUCCIÓN}

LA FILOSOFÍA HA ENCONTRADO EN EL «MAL» un límite incómodo, un lugar que le presenta un desafío único. Lo que pareciera jaquear este problema no es tal o cual teoría, sino la posibilidad misma de la comprensión (de cualquier tipo que ella fuera). Cuando enfrentamos el mal nos ponemos de cara al sinsentido, y sabemos bien que el pensamiento no puede habitar mucho tiempo en el sinsentido. El pensamiento se mueve dentro de los lindes del significado, cuando se aproxima a lo que está «por fuera del significado», a lo «absolutamente otro», tiende inevitablemente a integrarlo, y al hacerlo, lo transforma transformándose a sí mismo. Forma parte de la dinámica del pensar absorber todo a su paso.

El precio que el pensamiento debe pagar por extender sus fronteras más de allá de lo pensable, por abarcar cada vez más parcelas de realidad, es alto, tan alto que, en adelante, le costará mantenerse vigilante ante sus propios exabruptos y desmesuras. Por ello, el pensamiento deberá constantemente auto-denunciarse, revelar hacia adentro sus propias incapacidades y sucumbir agonalmente frente a lo que lo excede.

En este trabajo me detendré en un punto del pensamiento de Hannah Arendt que, al menos en una primera lectura, puede causar algo de perplejidad: la relación de interdependencia que establece entre la «comprensión» y la «reconciliación». Tomaré a Arendt (sin dudas una de las pensadoras más importantes del siglo XX) como una instancia de un problema que tiene su historia. No está en mi recorrer expositivamente los lineamientos generales del pensamiento arendtiano (no tengo la capacidad para hacerlo), mi intención es algo más humilde. Quiero detenerme en el problema de la comprensión y su relación con la reconciliación, analizar presupuestos, disparar algunas preguntas, relacionar el problema con la propuesta de otros autores que han analizado la cuestión.

\section{II.EL EXILIO: NOVEDAD Y EXTRAÑEZA}

«Todo lo que es incomprensible no deja por ello de ser». (B. Pascal 1993, p. 87).

En el origen del pensamiento arendtiano hay una experiencia dolorosa, traumática. El fenómeno del mal había hecho su descarnada y desquiciada 
aparición en los horrores del nazismo. Esa experiencia, de la cual nuestra autora fue testigo y víctima, no podía sino atravesarla completamente y actuar como promotora del pensar. Si bien es verdad que su obra recorre varios tópicos, es también cierto que esta experiencia permanece viva en cada una de sus palabras. Frente al acontecimiento del nazismo el pensar muestra toda su necesidad y algo de su incapacidad. Pero Arendt es hija de la larga tradición del logos, y no se rendirá fácilmente ante el problema. Llevará el pensamiento hasta el umbral del mal, para entablar una lucha desigual entre la necesidad de iluminar el acontecimiento y la desmesura que le presenta el fenómeno. Una cosa está presupuesta de antemano: no podremos habitar cómodamente un mundo en el que este acontecimiento no quede aclarado por medio de la comprensión; es decir, el desafío es mostrar que la comprensión es posible hasta en la desmesura.

Siempre la comprensión opera sobre un elemento que, al menos al principio, le es ajeno. Es decir, toda comprensión presupone que hay algo para comprender. «Comprender es el modo específicamente humano de estar vivo; pues toda persona individual necesita reconciliarse con un mundo al que nació como un extraño, y en el cual, en razón de la unicidad de su persona, sigue siendo por siempre un extraño». ${ }^{1}$ La categoría de extrañamiento se pone aquí como una de las razones por la cual es necesaria la comprensión. Lo que remarca esta noción es, al menos bajo cierto aspecto, la situación de separación que puede darse entre el sujeto y el mundo.

La comprensión se dirige, prima facie, a superar esa situación de distancia. La figura del extrañamiento frente al mundo está relacionada con otra figura que Arendt conocía bien: la del extranjero. Hay experiencias que provocan un corte, una suerte de exilio forzado. Frente a estas experiencias el juicio queda seriamente conmocionado. El mundo muestra un acontecimiento que supera cualquier intento de integrarlo en una familiaridad más amplia. La respuesta «específicamente humana» frente a lo irracional o incomprensible es, precisamente, la comprensión. La «comprensión», entonces, no es un extra opcional, algo que podamos eventualmente ejercer. Comprender es una «necesidad de la razón», una característica básica y distintiva del hombre, su «modo de habitar». Se trata de saber si esa necesidad puede ser siempre «colmada».

Uno de los presupuestos básicos de la comprensión es negar a-priori que el acontecimiento sea simplemente incomprensible, irracional. Es decir, cuando intentamos comprender suponemos que el fenómeno es comprensible. De aquí en más, se tratará de ver hasta qué punto la comprensión verifica el a-priori, o reconoce lo que está más allá de sus posibilidades. Si se da lo primero, lo extraño se hace familiar, pero si se da lo segundo entonces la situación se tornará cada vez más insostenible. 
Ahora bien, la comprensión existe antes de la ruptura. La dinámica del extrañamiento presupone una familiaridad que llega a su fin. Arendt subraya que el comprender es «el modo específicamente humano» de estar vivo. Se advierte aquí una resonancia heideggeriana: el comprender es una estructura óntica del Dasein, subyacente y más originaria que cualquier actitud epistémica. Por el hecho de vivir, de «habitar en», se teje una relación praxisiva con el mundo, relación que no tiene que ver con ninguna «objetivación», sino con la habitualidad del «tener-que-ver-con». Arendt deja entrever que esta estructura hermenéutica, constitutiva de la comprensión, hace difícil incorporar la dimensión de «corte», de «novedad», que parece estar implicada en toda verdadera ruptura. Heidegger, en línea con el último Husserl, destaca la dimensión de «horizonte de pre-comprensión» como la condición de posibilidad de toda comprensión. Si esto es así, sólo a la luz del horizonte previamente dado, es posible comprender. Ahora bien, la operatividad de la comprensión ante-predicativa hace difícil incorporar la categoría de «acontecimiento» en tanto absoluta novedad. Si hay horizonte dentro del cual se lleva a cabo toda posible comprensión, y si el acontecimiento implica, per definitionem, lo que no puede ser anticipado por ningún horizonte previo, entonces; si el horizonte es constitutivo de toda comprensión, la categoría de acontecimiento es del orden de lo imposible. Pero si el acontecimiento es imposible, no hay verdaderas rupturas, a no ser que lo imposible pueda ser real, o que lo irreal sea una posibilidad del acontecimiento. Por más paradójico que pueda sonar, Kristeva recuerda que Arendt «sostiene [...] que el totalitarismo se sustrae al entendimiento humano; más allá del antisemitismo, el horror ha alcanzado lo irreal». ${ }^{2} \mathrm{El}$ acontecimiento excede todo horizonte previo, es decir, provoca una des-horizontalización que deja a la comprensión sin orientación posible. Desde el momento en que hay horizonte el peligro consiste en diluir al acontecimiento, pues puede ocurrir que, una vez develado, el horizonte se ponga como eje de la comprensión provocando un olvido del acontecer, o sometiéndolo a una lógica foránea. Derrida advierte la situación: «Cuando hay un horizonte sobre el fondo del cual puedo determinar lo que sucede, en ese momento lo que sucede es secundario, previsible, programable, etc., y por lo tanto nada sucede verdaderamente. La condición del acontecimiento es la ausencia de horizonte». ${ }^{3}$

La experiencia de extranjerización desborda el perímetro del horizonte hermenéutico, es allí donde el hombre se enfrenta a lo verdaderamente nuevo, y en tanto tal, incomprensible. Esta incomprensibilidad no debe ser puesta sólo a cuenta de quien quiere comprender (no se trata de un defecto o incapacidad

2 J. Kristeva 2000, 162. Ver nota al pie: «Les techniques de la science sociale et l'étude des camps de concentration» (1950), en Arendt, Auschwitz et Jérusalem, pp. 203-220.

3 J. Derrida 1999, p. 49. 
propia del sujeto), sino que debe ser ubicada en la relación que une a quien desea comprender con el acontecimiento a comprender. Es la espesura de lo que sucede lo que sobrepasa nuestra capacidad de recepción. Puede ser esclarecedor recordar aquí la noción de «absurdo» de Albert Camus. El absurdo es una de las formas en que el acontecimiento hace su aparición (aunque no la única). Buena parte de la obra de Camus consiste en una lucha por rescatar la experiencia de lo que se presenta como «inabarcable» para la comprensión propiamente humana. «Cette épaisseur et cette étrangeté du mond, c’est l’absurde». ${ }^{4}$ Es interesante observar que Camus utiliza la misma figura que Arendt para señalar el carácter de extrañeza que suscita lo que rompe: la extranjerización, el divorcio entre el hombre y el mundo. ${ }^{5}$

Una desavenencia ruinosa separa al hombre de su circunstancia, de su campo de sentido. El divorcio supone una alianza que ha concluido, una desarmonización profunda que genera turbación. Camus remarca la tensión que define a esta situación de alejamiento, pues el hombre no puede dejar de desear la comprensión, aún frente a lo incompresible. ${ }^{6}$

El mal, el absurdo en la terminología camusiana, se presenta entonces como lo que deshace nuestras categorías de comprensión 7 . Es necesario detenerse en este momento de quiebre para advertir la dificultad que genera. Se trata de una verdadera dificultad, pues lo nuevo está llamado a dejar de ser lo que es ni bien es tocado por el pensar, por la comprensión.

Pero entonces, según lo que venimos insinuando, comprender es apropiarse de una realidad que se presenta extraña. Hacer propio significa, en este contexto, incorporarlo al horizonte de sentido. Esta integración modifica sustancialmente el horizonte, pues si bien es verdad que direccionar la atención al horizonte puede llevar a olvidar el acontecimiento (esto es lo que dice Derrida), también es verdad que el horizonte puede acoger el acontecimiento

4 [Esta espesura y esta extranjeridad del mundo es el absurdo] A. Camus 2006, 229.

5 Schaap recuerda que detrás de toda búsqueda de la reconciliación yace la contrafáctica referencia a la «unidad de la comunidad». La ruptura presupone cierta homogeneización que llega a su fin. No debemos olvidar, dice Schaap, el proceso de metaforización instalado en el corazón de la secularización de la noción de «reconciliación». Para más detalles cfr: Schaap Andrew: «The proto-politics of reconciliation». En Australian Journal of Political Science. 2006. 41/4, pags. 615-630.

6 «...Ce qui est absurde, c`est la confrontation de cet irrationnel et de ce désir éperdu de clarté dont l'appele resoné au plus profond de l'homme. L’absurde dépend autant de l’homme que du monde...». [«Lo que es absurdo es la confrontación de este irracional y del deseo apasionado de claridad que resuena en lo más profundo del hombre»]. Ibid, p. 233/4.

7 La experiencia del mal pareciera desechar en bloque todo horizonte de precomprensión. Lo nuevo ya no puede ser definido, sin pérdida significativa, en relación a lo viejo. La tradición ya no puede iluminar el presente. Arendt recuerda el aforismo de René Char: «nuestra herencia no está precedida de ningún testamento». $C f:$ H. Arendt 2004, p. 11. 
ampliando sus fronteras. El horizonte es algo que se puede ensanchar por medio del encuentro con lo que se le presenta como «exterior a él».

Ahora bien, esta integración apropiante puede generar la distorsiva sensación de estar en «posesión» de algo (¿el sentido?), de tener en nuestro patrimonio un capital del cual podemos disponer a voluntad. Apropiarse de lo extraño es, de algún modo, dominarlo. En esta dominación, una posibilidad es que el concepto le imponga al acontecimiento su propia regla, regla de subsunción según el juicio determinante. Lo obligue a «adecuarse» a la norma previamente establecida por el prejuicio. La otra posibilidad es que el comprender se modifique cuando se encuentra con el acontecimiento. Al toparse con lo que la supera, la comprensión se ensancha permitiendo un diálogo con la realidad. En este segundo caso se da una doble variación: varía el horizonte de comprensión (al ensancharse) y varía el objeto comprendido (al incorporarse al horizonte).

Resumamos lo dicho hasta aquí: hay experiencias que hacen estallar los márgenes del horizonte de comprensión. Dichas experiencias se hacen presente bajo el orden de lo excesivo, de lo desmesurado; siendo la medida nuestra capacidad de aprehensión. Lo que trasciende nuestra capacidad puede darse como lo «bajo» (hipo-infra) o como lo «alto» (hiper-supra), pero siempre como lo «meta-logos», lo «extraordinario», en el sentido de lo que yace fuera de los lindes del sentido. He aquí la relación de inconmensurabilidad que, en determinadas oportunidades, se da entre lo que se muestra y lo que puede ser categorizado. La realidad presenta una magnitud desmedida, y frente a esto, la comprensión queda aturdida. Cuando esto sucede, el acto de habitar el mundo queda sacudido en su fundamento, quedamos a la intemperie y necesitamos guarnecernos.

\section{EL CAMINO DE RETORNO}

«Un monde qu'on peut expliquer même avec de mauvaises raisons est un monde familier. Mais au contraire, dans un univers soudain privé d'illusions et de lumières, l'homme se sent un étranger» (A. Camus 2006, p. 223). ${ }^{8}$

Es interesante notar que Arendt, al tiempo que desarrolla la cuestión de la comprensión, advierte sobre una posible consecuencia o efecto que el comprender puede producir y que, según sus propias palabras, debemos, en ciertos casos, evitar. Por ello, junto con la caracterización positiva de la comprensión, hay que subrayar, una y otra vez, lo que la comprensión no es: «Comprender no significa negar lo atroz, deducir lo que no tiene precedentes a partir de

8 [Un mundo que podemos explicar aún con malas razones es un mundo familiar. Por el contrario, en un mundo repentinamente privado de ilusiones y de luces, el hombre se siente un extranjero]. 
ciertos precedentes, o explicar los fenómenos mediante analogías y generalidades que llevan a que ya no se sienta el impacto de la realidad y el shock de la experiencia». ${ }^{9}$ Hay aquí un elemento que juzgo decisivo en la posición arendtiana. El criterio de la verdadera comprensión puede medirse en términos de los «efectos» que esta produce. Es decir, hay un momento perlocutivo que acompaña toda verdadera comprensión. Si, como resultado de la supuesta comprensión, desaparece la fuerza del choque, entonces no hemos comprendido.

Arendt es conciente de una tentación que acecha a la razón cuando ésta es puesta de cara al «acontecimiento». Hay una enfermedad de la razón que consiste en «asimilar» lo pasmoso inesperado por medio de un distanciamiento alienante, de modo tal que, una vez provocada esa distanciación, el acontecimiento pierde su aire de novedad, y al hacerlo, provoca una merma de la fuerza del impacto. Se trata de un modo de apropiarse del acontecimiento que, por su misma lógica interna, genera una progresiva depreciación del choque, del shock. No debe perderse de vista esta necesidad de mantener a resguardo los «efectos» que provoca el encuentro con el acontecimiento, en este caso, terrible. Si la supuesta comprensión nos «aleja» del asombro, entonces algo anda mal en el modo como hemos enfrentado el acontecimiento.

Arendt ha vuelto en más de una ocasión al análisis de la actividad de pensar. Su análisis muestra una peculiar sensibilidad hacia una de las notas distintivas de todo pensamiento: su esencial alejamiento de la realidad sensible, de aquella realidad que asegura el sentido común. ${ }^{10}$ Utilizando una terminología que, seguro, le era familiar, podemos describir el momento en que se abre el pensar como un «suspender» nuestras actividades vitales, nuestra preocupación por las cosas del mundo práctico. Este «corte», que inaugura la reflexión, establece también una nueva relación con las cosas del mundo. Para «pensar» sobre algo, debemos «dejar de contar con ello». En este dejar de «contar con...» se trasluce la pérdida de fuerza vinculante que une al hombre con su mundo. Cuando pongo un «valor» como objeto de la reflexión pensante, ese valor ya ha dejado de valer.

Ahora bien, a diferencia del movimiento extranjerizante que produce el acontecimiento terrible, la epoche del pensar opera una «desvinculación inducida», no es algo que me ocurre, es algo que yo hago. Pero esta «distanciación comandada», que ejerce el pensar, puede redundar en un alejamiento cada vez más pronunciado, de modo tal que las preocupaciones y lazos, que nos unen al «mundo de las apariencias», se distienden más y más. Cuando el alejamiento nos aleja demasiado, las cosas de «este mundo» pueden perder su coloratura

9 H. Arendt 1999, p.VIII.

10 «...Para que podamos pensar en alguien, es preciso que este alejado de nuestros sentidos; mientras permanezcamos juntos no podemos pensar en él...». H. Arendt 2007, p. 166. 
habitual. Se trata de una de las posibilidades inmanentes del pensar. «Todo examen crítico debe pasar, al menos hipotéticamente, por un estadio que niegue los valores y las opiniones aceptadas buscando sus implicaciones y supuestos tácitos, y en este sentido el nihilismo puede ser visto como el peligro siempre presente del pensamiento» y un poco más atrás dice: «Lo que comúnmente denominamos nihilismo [...] en realidad es un peligro inherente a la actividad misma de pensar». ${ }^{11}$ Sólo advirtiendo esta posibilidad la razón puede implementar los anticuerpos necesarios para mantener a resguardo el acontecimiento.

Como afirma Arendt, para comprender ciertos fenómenos es improcedente el modelo nomológico deductivo, así como también ciertas generalidades y analogías. ¿Por que?, no sólo porque no lograran captar el fenómeno en toda su magnitud, sino también porque colaborarán con la desaparición de la sorpresa que éste produce. Si lo que sucedió era explicable en términos de «leyes» y «condiciones iniciales», entonces debemos aceptar que lo que ocurrió debía ocurrir, que era esperable, que era «natural que así sucediese». El conocimiento científico procede por «naturalización», es decir, negando lo extra-ordinario, o ubicándolo como mera variable estadística. ${ }^{12}$ Para este enfoque, la naturaleza no da saltos. Se aplica aquí el criterio perlocutivo de la comprensión; se juzga el modo de explicación científica de acuerdo al resultado que genera en relación al impacto provocado por el encuentro con lo que sucede. Para no caer en falsos modelos, Arendt subraya el carácter siempre provisorio que tiene la comprensión. ${ }^{13}$ La provisoriedad del comprender es la expresión cognitiva de la cualidad ontológica de la natalidad. Precisamente, el poder recomenzar

$11 \quad$ Ibid, p. 175.

12 En el caso de la explicación científica puede verse con claridad el decaimiento de la sorpresa, del choque provocado por lo que se presenta como incomprensible. Una vez dada la explicación científica, «lo que antes parecía tener un carácter un tanto mágico, ahora se comprende como un asunto banal. Y ésta es una característica habitual de toda explicación: la buscamos porque algo ha llamado nuestra atención aunque, una vez lograda y cuando el fenómeno se enmarca en el contexto de ciertos datos y ciertas leyes, repentinamente, lo que era un asunto enigmático e intrigante, se transforma en algo trivial. Por eso a veces se dice que una explicación consiste en una reducción a lo familiar...». G. Klimovsky - C. Hidalgo 2001, p. 32. Si aplicamos el criterio de los «efectos» vemos por qué Arendt deshecha la explicación científica frente al acontecimiento terrible; pues si seguimos el patrón nomológico-deductivo seremos arrastrados a una progresiva trivialización del mismo. Según la cita, una cierta banalización se produce en el conocimiento científico.

13 «La comprensión no tiene fin y por lo tanto no produce resultados finales; es el modo específicamente humano de estar vivo, ya que cada persona necesita estar reconciliada con un mundo al que vino como extranjera y en el cual $[\ldots]$ sigue siendo siempre extranjera...». Arendt: «Comprensión y Política», en C. Hilb 1994, p. 32. El carácter siempre abierto de la comprensión es puesto en relación con su finalidad reconciliadora. No hay, entonces, reconciliación final, porque no hay comprensión final. La inquietud es el tono general de quien quiere comprender. 
(principio óntico de la natalidad) es la condición trascendental de posibilidad del poder re-estructurar la comprensión.

La conmoción que provoca el encuentro con el acontecimiento se refleja, prima facie, en la incapacidad del lenguaje para nombrarlo. El horror del nazismo trastorna de tal manera la comprensión que esta enmudece por un instante, y luego comienza una búsqueda sin descanso para poder decir lo indecible. La «torpeza» del lenguaje se percibe con claridad sólo frente a determinadas experiencias para las cuales no encontramos la palabra adecuada, esto es, la palabra que logre decir y suscitar la densidad de lo vivido.

Sin embargo, una experiencia que permanece muda no está en condiciones de acceder a la dimensión del significado. Por ello, debemos operar un cambio de registro semántico que nos permita, al menos, circundar la experiencia del mal. El lenguaje es rico en recursos, tiene las herramientas para hacer emerger a la superficie de logos lo que aún se mantiene en la oscuridad de lo indecible. Una experiencia nueva, requiere una innovación semántica, una experiencia que conmueve amerita un lenguaje conmovido; y para ello debemos realizar una transposición de los códigos literales. Ricoeur ha sido uno de los que, en los últimos años, mejor ha advertido la relación entre profundidad de la experiencia del mal y necesidad del «lenguaje indirecto», «figurado». «No hay, en efecto, un lenguaje directo, no simbólico, del mal padecido, sufrido o cometido. Ya sea que el hombre se reconozca como responsable o como víctima de un mal que lo inviste, lo expresa desde el principio en una simbólica». ${ }^{14}$

La primera dificultad pareciera ser, entonces, lingüística. Cuando aparece la «novedad» no sabemos (bien) de lo que se trata hasta tanto no lo expresemos. El lenguaje es a un tiempo creativo y descriptivo. No inventa lo que sucede, pero tampoco lo refleja. La seriedad de la palabra yace en su capacidad de alumbramiento, en su efectividad para poder clarificar lo que ya está ahí.

La literalidad de los códigos lexicales está funcionalmente adherida a la habitualidad de ciertas experiencias. Es decir, el lenguaje se asienta en lo literal cuando, tanto el sentido como la referencia descansan en la familiaridad de lo «ya sabido». Por ello, cuando en el espacio de experiencia emerge lo extraño, el lenguaje necesita suspender la referencialidad primaria, literal, para abrir la dimensión metafórica. La metáfora es el recurso que tiene el lenguaje para habérselas con lo nuevo, con lo que rompe la habitualidad. En términos ricoeurianos, la metáfora, y todo discurso poético, no es un mero ornamento, un maquillaje que ponemos sobre algo pre-existente, sino que abre una nueva dimensión de la realidad que de otra forma no accedería al sentido. La metáfora no es un medio que podamos cambiar por otro, es el catalizador de una expe-

14 P. Ricoeur 1976, p. 27. 
riencia única. ${ }^{15}$ Esta capacidad de «innovación semántica» acerca la metáfora a la narración. Para Arendt, la configuración narrativa es el medio en el cual el acontecimiento revela algo de su sentido. En otras palabras, solo a la luz de la historia (en este caso, de la narración) los acontecimientos se hacen comprensibles. ${ }^{16}$ ¿Por qué?, porque la construcción de la trama opera una síntesis de elementos heterogéneos, dándoles unidad y permitiendo así que emerja el sentido. ${ }^{17} \mathrm{El}$ acto por el cual identificamos una «figura» en la masa aparentemente informe de los hechos se llama «configuración». ${ }^{18}$ Configurar es hacer de los «muchos» (incidentes, acciones, sentimientos, efectos deseados y no deseados, azares, personajes, lugares, etc.) «uno». El significado de los acontecimientos sólo se deja ver cuando lo disgregado se enlaza en una trama. Es esta idea de «lazo», de conjunción, lo que permite advertir la teleología implícita de los acontecimientos. Lo que sucede solo se hace inteligible cuando se muestra su inter-conexión; es decir, los acontecimientos no significan per se, sino por su lugar en el relato. En otras palabras, es la narración la que instaura la unión, aunque no la crea totalmente ya que toma sus elementos de la realidad. Lo que está en el fondo de este alegato en favor de la narración es la idea de que sólo en la totalidad (holos) aparece el sentido. Aunque las totalidades que recorta la narración son totalidades parciales, lo cierto es que «comprender es siempre captar una totalidad». ${ }^{19}$

La idea que el sentido solo hace su aparición en vista de la «totalidad» tiene una larga historia en la filosofía, de allí la pasión por «el todo» que manifiestan muchos pensadores: «Kant voyait aussi ce que d'autres avaient vu avant lui,

15 «(E)l discurso poético transforma en lenguaje aspectos, cualidades y valores de la realidad, que no tienen acceso al lenguaje directamente descriptivo y que sólo pueden decirse gracias al juego complejo entre enunciación metafórica y la transgresión regulada de las significaciones corrientes de nuestras palabras. Por consiguiente me he arriesgado a hablar no sólo de sentido metafórico, sino de referencia metafórica, para expresar este poder que tiene el enunciado metafórico de re-describir una realidad inaccesible a la descripción directa. ...». P. Ricoeur 1995, p. 33.

16 «Qui dit ce qui est -legein ta eonta- raconte toujours une histoire, et dans cette histoire les faits particuliers perdent leur contingence et acquièrent une signification humainement compréhensible. ...». [Quien dice lo que es, legein ta eonta, cuenta siempre una historia, y en esta historia los hechos particulares pierden su contingencia y adquieren una significación humanamente comprensible]. H. Arendt 2004, p. 333.

17 Arendt relaciona conceptualmente totalidad-narración-juicio reflexionante y significado. En este sentido, es necesario retomar los análisis arendtianos en torno a la filosofía política de Kant, y al tipo de «juicio» allí desarrollado. No tengo espacio suficiente para mostrar esta importante relación, remito para ello a Neus Campillo (2002), «Comprensión y Juicio en Hannah Arendț, en Revista Daimon, número 26. pags. 125-140.

18 Para un tratamiento más detallado del acto configurante, cfr: P. Ricoeur 1995, pp. 80-113.

19 P. Ricoeur 1990, p. 157. 
que dès que l'on condirère 1'histoire en son entier (im Grossen), plutôt que les événements singuliers et les intention toujours déçues des acteurs, tout prend soudain du sens, parce qu'il y a toujours au moins une histore à raconter». ${ }^{20}$

El narrador comparte con el pensador la misma actitud «contemplativa»: cuando narramos no actuamos, esto da al narrador (espectador) la posibilidad de ver lo que está vedado a los actores. La reticularidad de la narración coloca al narrador más allá de las intenciones de los participantes. Sólo en la mirada narrativa surge la asimetría entre lo que «buscaban los actores» y lo que verdaderamente sucedió. Por ello afirma Arendt: «La acción sólo se revela plenamente al narrador, es decir, a la mirada del historiador, que siempre conoce mejor de lo que se trataba que los propios participantes». ${ }^{21}$ La narración es la mediación entre los acontecimientos y su sentido; y donde hay sentido la reconciliación es posible.

\section{NuEVAMENTE EN CASA}

«Precisamente porque sufrimos bajo las condiciones del desierto todavía somos humanos y aun seguimos intactos; el peligro está en llegar a ser verdaderos habitantes del desierto y en sentirse en él como en casa». (H. Arendt 2008, p. 225)

Llegados a este punto podríamos preguntar: ¿qué fue de la categoría de lo «impensable», de lo que «excede» el horizonte de comprensión? Si el sentido es el medio del cual vive el pensar, entonces, lo que escapa al logos es imposible, «retórica de niños»: «Lo otro, quedándose inmóvil junto a la razón, es solamente palabrerío». ${ }^{22}$ Pareciera que «lo otro» (¿lo otro del sentido?), al igual que Eurídice, está llamado a desaparecer desde el momento en que lo miramos.

Arendt se enmarca en la tradición de aquellos que apostaron por el logos: «La necesidad de la razón consiste en dar cuenta, logon didonai, como la denominaban los griegos con gran precisión, de todo lo que puede existir o puede haber acontecido». ${ }^{23}$ Este «dar cuenta de la realidad» es el pre-requisito para la reconciliación.

Decía más arriba que un mecanismo de apropiación está implícito en todo comprender. Este mecanismo no deja intacto el modo anímico disposicional

20 [Kant vio también aquello que otros habían visto antes que él, que desde que se considera la historia en su totalidad antes que los acontecimientos singulares y las intenciones declaradas por los actores, todo adquiere repentinamente sentido, por que hay siempre una historia que contar]. Ibid, p. 110.

21 H. Arendt 1998, p. 215. Y agrega: «Aunque las historias son los resultados inevitables de la acción, no es el actor, sino el narrador, quien capta y 'hace' la historia». (idem).

22 G.W.F Hegel 2008, p. 21

23 H. Arendt 2002, p. 122. 
que nos relacionaba con la cosa a comprender. La comprensión modifica la relación entre quien comprende y lo que es comprendido. Arendt afirma que la «reconciliación es inherente a la comprensión». Estamos aquí frente a un punto central de su pensamiento. ¿Qué significa que la comprensión reconcilia? La pregunta gana en densidad si ponemos la comprensión frente a las experiencias límite. Es importante señalar que, según Arendt, la reconciliación no se da con el fenómeno aislado. Nos reconciliamos, dice la autora, con el mundo, con un mundo en el que eso ha sido posible.

Hay que subrayar la relación de «inherencia» que une «comprensión»y «reconciliación». Creo que la relación corre para uno de los lados: si hay comprensión entonces hay reconciliación. Esta es una premisa fuerte del argumento arendtiano, pues niega la posibilidad que haya comprensión sin reconciliación. Aunque la premisa deja abierta la posibilidad de que exista reconciliación sin comprensión.

Puede suceder, y de hecho sucede en muchas ocasiones, que lo que antes de la comprensión nos generaba estupor, terror, o inclusive admiración; una vez comprendido cambie estas disposiciones anímicas. El comprender modifica la fisonomía de lo que antes estaba sin comprenderse. Es clásico ya el caso de aquél que, frente al perjurio cometido por su amigo, siente una gran indignación; indignación que desaparece cuando advierte que el perjurio estaba motivado por razones más que justas. La indignación deja lugar a la compasión a causa de la nueva apreciación sobre el hecho. Al saber lo que no sabía, comprende, y al comprender modifica su relación. Un proceso de re-evaluación está al final de todo acto cognitivo.

Esto se aprecia con claridad en el problema del mal, cuando el mal es comprendido desaparece como tal, es decir, deja de ser el mal, pues ahora, una vez comprendido, tiene sentido. Ricoeur lo expresa en estos términos: «Il est à peine besoin de souligner que le mal est le point critique de toute pensée philosophique: si elle le comprend, c'est son plus succès; mais le mal compris n'est plus le mal, il a cessé d'être absurde, scandaleux, hors droit et hors raison». ${ }^{24}$ Comprender el mal es disolverlo. Pero una vez disuelto, ¿puedo aún indignarme?, ¿se da todavía el shock?

Hay una cercanía entre Ricoeur y Arendt en este punto. Para ambos, la comprensión modifica la relación entre el sujeto y lo comprendido. Pero, en el caso de Ricoeur, pareciera ser más explícita la referencia a la disminución, o desaparición, del carácter conmocionante del acontecimiento por obra de la misma comprensión. Si, una vez comprendido, el mal deja de ser «escandaloso»,

24 [Es necesario subrayar que el mal es el punto crítico de todo pensamiento filosófico. Si lo comprende, es su más alto éxito, pero el mal comprendido no es más el mal, ha cesado de ser absurdo, escandaloso, fuera de derecho y fuera de razón]. P. Ricoeur 1992, p. 16. 
entonces ya no hay motivos para shockearse. En el fondo, toda comprensión es tranquilizadora. La característica que, retomando la terminología camusiana, genera el «rechazo», la «révolte», es lo «absurdo», el sinsentido; de modo tal que si este desaparece, aquél también. Y, una vez desaparecido el rechazo, está el camino allanado para la «reconciliación». Arendt manifiesta una gran confianza en el poder reconciliador de la narración. «Il est parfaitement vrai que 'tous les chagrin peuvent être supportés si on les transforme en histoire ou si l'on raconte une histoire sur eux'». ${ }^{25} \mathrm{Y}$, un poco más adelante retoma un clásico tópico de la filosofía. El texto merece citarse in extenso:

«Dans la mesure où celui qui dit la vérité de fait est aussi un raconteur d 'historie, il accomplit cette 'réconciliation avec la réalité' que Hegel, le philosophe de l'histoire par excellence, comprit comme le but ultime de toute pensée philosophique, et qui, assurément, a été le moteur secret de toute historiographie que transcende la pure érudition. La transformation du matériau brut donné des simples événements que l'historien, comme le romancier [...] doit effectuer est étroitement apparentée à la transfiguration poétique des états d’âmes ou des mouvements du coeur, la transfiguration de la douleur en lamentation ou de l'allégresse en célébration. Nous pouvons voir, avec Aristote, dans la fonction politique du poète, la mise en oeuvre d une catarsis, purification de toutes les passions que pouvent empêcher l'homme d agir. La fonction politique du raconteur d 'histoire -historien ou romancier-est d'enseigner l'acceptation des choses telles quelle sont». ${ }^{26}$ Aquí Arendt habla de la función del narrador de historias equiparando, al menos por un momento, al novelista con el historiador. Ambos buscan «aceptar» la realidad, «amigarnos con ella». El relato logra ese efecto porque «da forma a lo informe», y de esta manera lo completa sin necesidad de huir de él. En el relato aparece el sentido, y sólo el sentido parece colmar. ${ }^{27}$

25 [Es ciertamente verdadero que «todas las penas pueden soportarse si las transformamos en historia o si contamos una historia sobre ellas»]. H. Arendt 2004, p 333. Esta cita, que toma de Isak Dinesen, la repite como epígrafe del capítulo dedicado a la acción en La Condición Humana.

26 [En la medida en que aquel que dice la verdad de los hechos es también un contador de historias lleva a cabo aquella «reconciliación con la realidad» que Hegel, el filósofo de la historia par excellence, toma como el fin último de todo pensamiento filosófico, y que ha sido el motor secreto de toda historiografía que trasciende la pura erudición. La transformación del material bruto dado de simples acontecimientos que el historiador, como el narrador (...) debe realizar está estrechamente emparentada con la transfiguración poética de los estados del alma o de los movimientos del corazón, la transfiguración del dolor en lamentación o de la alegría en celebración. Podemos ver, con Aristóteles, en la función política del poeta, la puesta en obra de una catarsis, purificación de todas las pasiones que pueden impedir que el hombre actúe. La función política de contar historias, historiador o narrador, es la de enseñar la aceptación de las cosas tal como son]. Ibid, p. 334.

27 Camus alude al mismo poder iluminador del relato: «Qu'est-ce que le roman, en effet, sinnon cet univers oú l'action trouve sa forme, les mots de la fin sont prononcés, les êtres livrés 
Veo un desplazamiento importante en el modo de apreciar los efectos de la comprensión en el tratamiento arendtiano. El «soportar» connota un cargar, llevar a cuestas. Pero quien carga puede aún elevar una queja, rebelarse (Camus) frente a lo que le obliga a llevar el peso. Pero esta posibilidad de rechazo, aún en lo inexorable, pareciera desvanecerse desde el momento en que la autora afirma que la finalidad política de narrar la historia (y, por lo tanto, del comprender) es enseñar a «aceptar las cosas tal como son». Un deslizamiento muy significativo se aprecia entre «soportar» y «aceptar». La sobresignificación metafórica muestra la interconexión entre «pesar» y «soportar». Cuando el acontecimiento tiene un peso que sobrepasa la capacidad de sostén del relato, entonces, la «trama» (el tejido narrativo) se «rompe». ${ }^{28}$

Ahora bien, hay dos formas de comprender la categoría de «aceptación». Por un lado puede tratarse del reconocimiento de una situación de hecho existente («acepto que así son las cosas»), y también existe la aceptación como asentimiento, en este caso, la fuerza ilocutiva de la «aceptación» esconde un momento de afirmación, un aprobación, al menos parcial, a la realidad. Aceptar, en el segundo sentido, es consagrar un acuerdo aun en las diferencias, acuerdo que permite reconciliarnos con lo que hemos reconocido. Así, una armonización se reestablece en el instante de la aceptación. Pero no habría tal instante si la comprensión no hubiese hecho emerger el «sentido». ${ }^{29}$

En la misma línea que Aristóteles, Arendt señala que la «transformación» narrativa, operada sobre el «material en bruto de los hechos», genera una «transfiguración» (poética) de nuestros sentimientos, o más precisamente, nuestros «estados del alma». Esta reconversión de los sentimientos (y disposiciones

aux êtres, où toute vie prend le visage du destin.». [Qué es, en efecto, una novela sino ese universo donde la acción encuentra su forma, las palabras del fin son pronunciadas, los seres liberados a ellos mismos, donde toda vida adquiere el aspecto del destino]. A. Camus 2008, p. 287.

28 Cruz afirma que el acontecimiento es lo insoportable por la trama narrativa. «... En ocasiones, ocurre algo que, siendo conocido, sobrepasa con mucho la medida y el tamaño conocidos y, en la misma proporción asimilables por nuestros relatos. Ni el mal ni el bien han sido nunca ajenos a la condición humana, pero en un momento dado alguien puede traspasar las imaginarias fronteras de la normalidad y adentrarse en los territorios de lo extraordinario, que puede ser de carácter espantoso o de carácter heroico». M. Cruz «Memoria. ¿extrañeza o reconciliación», en VV.AA. 2006, p. 90.

29 «Un relato adecuado es aquel que permite ir incorporando cuanto ocurre, mientras que, por su parte, una experiencia cargada de sentido es aquella en la que las cosas que nos van ocurriendo, por sorprendentes que en un primer momento puedan parecer, de inmediato encuentran su lugar en el espacio narrativo» Idem. Nuevamente la sorpresa se da en el momento anterior al relato. Si esto es así, entonces luego del relato, la sorpresa desaparece. Hay una "X» tal que «X $»$ genera la abolición de la sorpresa. Esta «X»» puede ser tanto la explicación científica como la narración de los hechos. La diferencia entre ambos pareciera reducirse al modo en que se obtiene el fin. 
afectivas), causada por el modo de contar, es decir, por el modo de ordenar lo aparentemente informe a través del mythos, es la llave de la reconciliación.

De esta manera, el «relato» funciona como medio de familiarización con aquello que se nos ha enajenado. Opera una dialéctica entre lo esperable y lo imprevisto que termina por armonizar la disonancia. Se trata de un mecanismo que serena, pues re-ordena el horizonte de sentido volviendo habitable el mundo.

La palabra exorciza, por ello nos permite una reconciliación. Cuando nombramos al extranjero, al recién llegado, lo hacemos parte de la familia, lo familiarizamos modificando de esta manera su antigua condición. En el rito bautismal se condensa la lógica de la comprensión, pues dar un nombre es dar acogida, es decretar la bienvenida «al recién llegado». Nombrar acorta una distancia, genera un lazo de parentesco haciendo desaparecer el sinsentido. ${ }^{30}$ $\mathrm{Si}$ algo tiene nombre ya no nos es incompresible, ya no se antepone como «lo otro», sino que comienza a ser parte de nosotros. Bautizar es sacar del «anonimato», es instaurar una unicidad, una identidad irreductible. «El mero dar nombre a las cosas, la creación de palabras, es la manera humana de apropiarse y, por decirlo así, de 'desalienar' el mundo al que, después de todo, cada uno de nosotros viene como un recién llegado y un extranjero». ${ }^{31}$

Ahora bien, el lenguaje, inclusive el lenguaje poético (metáfora, narración) también se expone al efecto corrosivo del tiempo, tiempo de de repetición que va horadando la novedad. Un proceso de sucesivas iteraciones llevan al desgaste de la metáfora y el relato. La metáfora, la novela, también padecen su propia dinámica nihilizante. La narración puede ser otra forma de domesticar lo extra-ordinario. Este «uso irénico» del relato es el que subraya Bruner: «Contar historias es nuestro instrumento para llegar a un acuerdo con las sorpresas y lo extraño de la condición humana. [...] Las historias hacen menos sorprendente, menos arcano, lo inesperado, le dan un aura análoga a la cotidianidad $» .{ }^{32}$ Cuando el relato hace ordinario lo extraordinario hay que contar de otra manera. El agotamiento de la narración va de consuno con su incapacidad de revelación.

La progresiva repetición deviene en un olvido del momento de innovación. El lenguaje se pragmatiza, se acuña en frases que, conforme se cristalizan, pierden su aura original y ya no suscitan la modificación «de los estados del

30 Ciertas palabras, tienen un efecto conjurador; modifican la realidad: «Si même le roman ne dit que la nostalgie, le désespoir, l'inachevé, il crée encore la forme et le salut. Nommer le désespoir, c’est le dépasser». [Si aún la novela no dice más que la nostalgia, la desesperación, el inacabamiento, ella crea todavía la forma y la salvación. Nombrar la desesperación es superarla]. C. Camus 2008, p. 287.

31 H. Arendt, 2002, p. 122.

32 J. Bruner 2003, p. 126. ¿No se produce aquí un efecto análogo al que se produce en el conocimiento científico? Sea por medio del modelo nomológico-deductivo, sea por medio del «contar historias», la sorpresa mengua. 
alma». Por el contrario, cuando la innovación ya no deja ver la impertinencia predicativa, pierde su capacidad reconciliante. En ocasiones, el destino del relato es morir paulatinamente hasta transformarse en cliché. El cliché, a su vez, transforma la tensión en desdén. Cuando hay desdén no hay verdadera reconciliación, hay desinterés, indiferencia. Las condiciones están dadas para que se produzca el olvido.

Arendt se esfuerza por mantenerse alejada de las «filosofías de la historia»; aquellas que ven en el devenir del espíritu la realización progresiva de una idea que mueve los hilos a espaldas de los hombres. Estas filosofías, con Hegel a la cabeza, tratan de ir a la búsqueda de una finalidad en los acontecimientos históricos, finalidad que representa un verdadero progreso y que justifica la aparición del mal. En este sentido, el mal desaparece cuando advertimos el «plan» superior al que sirven los hechos. Cuando los acontecimientos son ubicados dentro del desenvolvimiento lógico de una idea, estamos en presencia de la forma secularizada de la teodicea.

Sin embargo, más allá de la autocomprensión de Arendt, creo que hay una conexión lógica entre su idea de la relación «narración-comprensiónreconciliación» y las clásicas teodiceas. Podemos llegar a esta conclusión cuando vemos que la lógica de la narración consiste, al igual que la lógica de la teodicea, en mostrar de qué manera lo que parece absurdo está llamado a adquirir sentido cuando lo ponemos en relación con otra cosa. Al establecer la conexión desaparece el sinsentido. Lo que yace detrás de esto es que por medio del «encadenamiento», la «conexión», se supera la ininteligibilidad, y esta superación nos devuelve a lo sensato. La reconciliación sólo se da por la previa emergencia del sentido, y el sentido es una propiedad del «todo» captado narrativamente. Pero, cuando el relato nos reconcilia podemos estar cerca de la teodicea. En su versión secularizada, «la teodicea [...] es la tentación de hallar algún [...] modo de reconciliarnos con el mal y el sufrimiento inútil, intolerable......33

Es el tejido/trama el que hace emerger la significación. La matriz procedimental sigue siendo el «tomar juntos» (com-poner). No estoy seguro de que nos encontremos muy lejos de las viejas propuestas reconciliadoras de las clásicas

33 R. Bernstein 2004, p. 237. Una línea crítica referida a la cuestión del «sentido de la historia» se refiere a la cripto-justificación teleológica que muestra todo supuesto sentido. El problema es que la historia tiene costos muy graves (destrucción, aniquilación, dolor, etc). Así dice Koselleck: «luego de que el absurdo se transformase en acontecimiento, no debiera recibir la absolución de pretender que tiene sentido». Koselleck R. «Vom Sinn und Unsinn der Geschichte», en K. Müler y J. Rüsen (eds.), Historiche Sinnbildung. Rowohlts Enzyklopädie, Hamburgo 1997. Pag. 96-7. Citado por Belvedresi R., El sentido de la historia. En M. Cruz - D. Brauer (comps.) 2005, p. 98. 
teodiceas ${ }^{34}$ En ambos casos se trata de «ampliar la mirada», ya que en esa ampliación (en la que aprehendemos un acontecimiento en su relación con otros) se revelará el «significado». La única manera de evitar el corrimiento de la narración hacia una teodicea secularizada, es recordando que la tendencia hacia la «totalidad» puede redundar también en el desprestigio de lo individual. ${ }^{35}$ Si el sentido es una propiedad del «todo» (aunque sean totalidades parciales), entonces no siempre es verdad que lo que se da en el todo se da en la parte.

Es aquí donde el sentido juega en los lindes de la justificación. Cuando detectamos el sentido entonces desaparece el sinsentido, y era esto lo que mantenía abierta la herida del escándalo. Es decir, si miro la trama totalizante, lo que queda obliterado es el carácter singular del acontecimiento; este es el requisito para poder volver a estar en casa en el mundo. La habitabilidad del mundo, su carácter de ethos (lugar en el que se está en el modo de lo ya habitado y por tanto habitable) presupone cierta familiaridad. Cuando estamos en casa, estamos tranquilos porque es el lugar de la hiper-familiar.

Si esto es así, entonces la percepción del absurdo sería la consecuencia lógica de quién toma el suceso en forma aislada, es decir, de quien separa, escinde. Hegel llama «abstracción» a este proceder del entendimiento separatista. Poner en relación significa, para la trama, dirigir la mirada a dos o más hechos, suceso, acontecimientos, para mostrar lo que los une. Pero la experiencia del mal, el escándalo de lo incomprensible, pide un aislamiento total. Más allá de algunas posibles aporías en su cartografía categorial, Arendt siempre intentó rescatar la «contingencia», la particularidad, del conato generalizante del pensamiento. ${ }^{36}$ Hay acontecimientos cuya «unicidad» repele cualquier intento de «relación». ${ }^{37}$ Si comprender es «unir», estos acontecimientos son «incomprensibles».

34 No me estoy refiriendo a la teodicea en tanto justificación de Dios, sino al modo en que se busca esta justificación, es decir, superando el mal disolviéndolo.

35 «Chez Kant, qui contraste à cet égard avec Hegel, le mobile de l'evasión moderne de la politique dans l'histoire est encore tout à fait clair. C'est l'évasion dans le «tout», et l'evasión est inspirée par l'absence de sens du particulier». [En Kant, que en esto contrasta con Hegel, el móvil de la evasión moderna de la política en la historia es todavía claro. Se trata de la evasión en el «todo», evasión inspirada en la ausencia de sentido de lo particular]. H. Arendt, 2004, p. 111.

36 «Le mépris du particulier au profit de l'universel caractérise aussi bien les sciencies de la nature que l'hisoire, peut-être jusqu'a les apparenter. Mais en même temps, ne peut-on pas y voir le prélude à une possible 'perte de contact' avec la réalité mondaine qui signifierait, dans les termes de Hannah Arendt, une 'ruine du sens commun', dans laquelle se prépare selon elle le règne de la terreur? » [El desprecio de lo particular en beneficio de lo universal caracteriza tanto las ciencias de la naturaleza como la historia, hasta el punto de emparentarlas. Pero, al mismo tiempo, ¿no podríamos ver el preludio a una posible «pérdida de contacto» con la realidad mundana que significaría, en los términos de Arendt, una «ruina del sentido común», con la que se prepara, según ella, el reino del terror?]. A. Hubeny 1993, p. 122.

37 Ricoeur advierte la tendencia explicativa de todo intento componedor, y señala ciertos 


\section{CoNCLUSIÓN}

Comprender puede ser un mecanismo de adaptación. La razón de esta adaptación es clara; nos resulta difícil habitar la tensión frente a lo extraño, a lo que supera nuestras categorías de pensamiento. La tendencia es normalizar lo extra-ordinario, y al hacerlo, disolverlo en tanto tal. Quizá por ello Arendt insiste en el carácter provisorio de la comprensión: «[L]a comprensión, en cuanto diferente de la información correcta y del conocimiento científico, es un proceso complicado que no produce nunca resultados inequívocos. Es una actividad sin fin por la cual, en el cambio y la variación constantes, nos adaptamos a la realidad, nos reconciliamos con ella, es decir, tratamos de sentirnos cómodos en el mundo»». ${ }^{38}$

Sin embargo, y siguiendo el criterio perlocutivo de la comprensión, la autora reconoce que hay ciertas situaciones con las que no debemos conciliar. Cualquier intento de familiarizarse con esas situaciones provocaría una merma de nuestra capacidad para verse «afectado» por la experiencia. En su conclusión al programa de conferencias titulado «La historia de la teoría política» (que dio en la Universidad de California en la primavera de 1955) Arendt retoma la metáfora del desierto como figura que describe la consumación del nihilismo europeo. Allí observaba el peligro de adaptarse al desierto eliminando del horizonte los oasis que mantienen la necesidad de la lucha. Es conciente de los mecanismos de acomodación y por ello subraya la necesidad de mantener alerta la comprensión, pues «...si aquellos que están obligados a pasar sus vidas en el desierto, intentando hacer esto o aquello, preocupándose constantemente por sus condiciones, no saben como usar los oasis, se convertirán en habitantes del desierto (...). En otras palabras, los oasis, que no son lugares de 'relajación', sino fuentes de vida que nos permiten vivir en el desierto sin reconciliarnos con él, se secarán...» $\rangle^{39}$. Una declaración que pone a una de las pensadoras políticas más importantes del siglo XX en el límite mismo de la política cuando reconoce que estos oasis son «...aquellas parcelas de la vida que existen independientemente, o casi, de las condiciones políticas...» ${ }^{40}$.

acontecimientos que, por su carácter único, no se dejan poner en relación. «Respecto a esta individuación y también a la individualización por el tiempo [...] hablaría gustosamente de acontecimientos únicamente únicos. Cualquier otra forma de individuación es la contrapartida de un trabajo de explicación que une. El horror aísla al hacer incomparable, incomparablemente único, únicamente único». P. Ricoeur 1996, p. 911.

38 C. Hilb 1994, p. 33.

39 H. Arendt 2008, p. 226.

40 Idem. 


\section{BIBLIOGRAFÍA}

ARENDT H. 1998: La Condición Humana. Barcelona. Paidós.

—, 1999: Los orígenes del totalitarismo. Madrid. Taurus.

-, 2002: La Vida del Espíritu. Buenos Aires. Paidós.

-, 2004: La Crise de la Culture. Paris. Gallimard.

—, 2005: Ensayos de Comprensión. Madrid. Caparrós.

—, 2007: Responsabilidad y Juicio. Barcelona. Paidós.

—, 2008: La promesa de la política. Barcelona. Paidós.

BERNSTEIN R. 2004: El mal radical. Buenos Aires, Lilmod.

BRUNER J. 2003: La fábrica de historias. Bs. As. FCE.

CAMUS A. 2006: Le Mythe de Sisyphe. Oeuvres Complètes. I. Paris. Gallimard.

—, 2008: L'Homme Révolté. Oeuvres Complètes III. Paris. Gallimard.

CRUZ M. Brauer D, (comps.) 2005: La Comprensión del pasado. Barcelona. Herder.

DERRIDA J. 1999: Sur parole. Instantanés philosophiques. Edition de l’Aube, Paris.

HEGEL G-W.F. 2008: Lecciones de Filosofía de la Historia. Buenos Aires. Claridad.

HILB (comp.). 1994: El Resplandor de lo Público. Caracas. Nueva Sociedad.

HUBENY A. 1993: L'action dans l'oeuvre de Hannah Arendt. Paris. Larousse.

KLIMOVSKY G. - Hidalgo C. 2001: La inexplicable sociedad. Buenos Aires. A-Z editores.

KRISTEVA J. 2000: El genio femenino. 1-Hannah Arendt. Bs. As. Paidós.

PASCAL B. 1993: Pensamientos. Barcelona. Altaya.

RICOEUR P. 1976: Introducción a la Simbólica del Mal. Buenos Aires. Megápolis.

—, 1990: Historia y Verdad. Madrid. Encuentro.

-, 1992: Lectures II. La contrée des philosophes. Paris. Seuil.

-, 1995: Tiempo y Narración I. México. SXXI.

—, 1996: Tiempo y Narración III. México. SXXI.

VV.AA. 2006: El siglo de Hannah Arendt. Barcelona. Paidós.

SCHAAP Andrew (2006), The proto-politics of reconciliation. En Australian Journal of Political Science. 41/4.

NEUS Campillo (2002), Comprensión y Juicio en Hannah Arendt, en Revista Daimon, número 26.

Juan Ignacio Blanco es Doctor en Filosofía, Licenciado en Filosofía y Profesor de Filosofía en la UNLP.

Línea de investigación

El problema de la comprensión en la filosofía del siglo XX. 
Publicaciones recientes

(2012) «Hermenéutica de la Ipseidad». CABA. Editorial Biblos. Colección Tesis. 351 paginas. ISBN: 978-950-786-934-1.

(2013) «Albert Camus: el arte como transfiguración de la experiencia». Revista Criacão e Critica. Universidad de Saõ Paulo. ISSN: 1984-1124. Revista indexada, con referato internacional. En Prensa (26/2/2013).

Dirección electrónica: juan_blanco2001ar@hotmail.com 